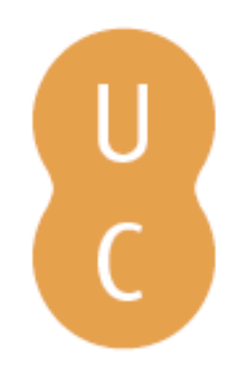

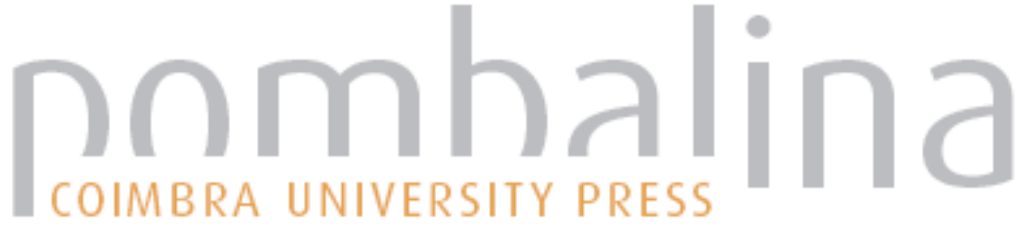

\section{Coupled fire-atmosphere-smoke forecasting: current capabilities and plans for the} future

\author{
Autor(es): $\quad$ Kochanski, Adam K.; Mandel, Jan; Vejmelka, Martin; Burke, Dalton; \\ Hearn, Lauren; Haley, James; Caus, Angel Farguell; Schranz, Sher
}

Publicado por: Imprensa da Universidade de Coimbra

URL persistente:

URI:http://hdl.handle.net/10316.2/44621

DOI:

DOI:https://doi.org/10.14195/978-989-26-16-506_104

Accessed : $\quad$ 26-Apr-2023 14:23:33

A navegação consulta e descarregamento dos títulos inseridos nas Bibliotecas Digitais UC Digitalis, UC Pombalina e UC Impactum, pressupõem a aceitação plena e sem reservas dos Termos e Condições de Uso destas Bibliotecas Digitais, disponíveis em https://digitalis.uc.pt/pt-pt/termos.

Conforme exposto nos referidos Termos e Condições de Uso, o descarregamento de títulos de acesso restrito requer uma licença válida de autorização devendo o utilizador aceder ao(s) documento(s) a partir de um endereço de IP da instituição detentora da supramencionada licença.

Ao utilizador é apenas permitido o descarregamento para uso pessoal, pelo que o emprego do(s) título(s) descarregado(s) para outro fim, designadamente comercial, carece de autorização do respetivo autor ou editor da obra.

Na medida em que todas as obras da UC Digitalis se encontram protegidas pelo Código do Direito de Autor e Direitos Conexos e demais legislação aplicável, toda a cópia, parcial ou total, deste documento, nos casos em que é legalmente admitida, deverá conter ou fazer-se acompanhar por este aviso.

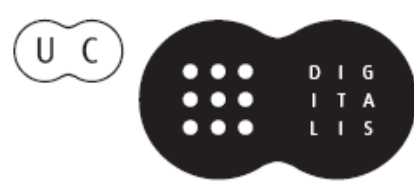




\section{ADVANCES IN}

\section{FOREST FIRE RESEARCH}

\section{8}

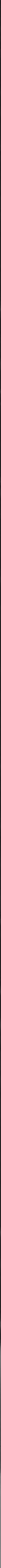




\title{
Coupled fire-atmosphere-smoke forecasting: current capabilities and plans for the future
}

\author{
Adam K. Kochanski ${ }^{1 *}$; Jan Mandel²; Martin Vejmelka ${ }^{3}$; Dalton Burke²; Lauren Hearn ${ }^{2}$; James \\ Haley $^{2}$; Angel Farguell Caus ${ }^{4}$; Sher Schranz ${ }^{5}$ \\ ${ }^{1}$ University of Utah. Salt Lake City, Utah, \{adam.kochanski@utah.edu*\} \\ ${ }^{2}$ University of Colorado Denver. Denver, Colorado, \{jan.mandel@ucdenver.edu, \\ dalton.burke@ucdenver.edu,lauren.hearn@ucdenver.edu,james.haley@ucdenver.edu\} \\ ${ }^{3}$ CEAi, Inc., Prague, Czech Republic,0000-0003-2309-5869, \{vejmelkam@gmail.com\} \\ ${ }^{4}$ University of Colorado Denver and Autonomous University of Barcelona. Denver, Colorado, \\ \{angel.farguell@gmail.com\} \\ ${ }^{5}$ Colorado State University, Ft. Collins, Colorado \{sher@rams.colostate.edu\}
}

\begin{abstract}
In this paper, we present an integrated wildland fire forecasting system based on combining a high resolution, multi-scale weather forecasting model, with a semi-empirical fire spread model and a prognostic dead fuel moisture model. The fire-released heat and moisture impact local meteorology which in turn drives the fire propagation and the dead fuel moisture. The prognostic dead fuel moisture model renders the diurnal and spatial fuel moisture variability. The local wind and the fuel moisture variation drive the fire propagation over the landscape.

The sub-kilometer model resolution enables detailed representation of complex terrain and small-scale variability in surface properties. The fuel moisture model assimilates surface observations of the 10h fuel moisture from Remote Automated Weather Stations (RAWS) and generates spatial fuel moisture maps used for the fire spread computations. The dead fuel moisture is traced in three different fuel classes $(1 \mathrm{~h}, 10 \mathrm{~h}$ and $100 \mathrm{~h}$ fuel), which are integrated at any given location based on the local fuel description, to provide the total dead fuel moisture content at the fire-model grid, of a typical resolution of tens of meters.

The fire simulations are initialized by a web-based control system allowing a user to define the fire anywhere in CONUS as well as basic simulation properties, such as simulation length, resolution, and type of meteorological forcing for any time meteorological products are available to initialize the weather model. The data is downloaded automatically, and the system monitors execution on a cluster. The simulation results are processed while the model is running and displayed as animations on a dedicated visualization portal.
\end{abstract}

Keywords: Fire forecasting, Plume rise, WRF-SFIRE, WRFX, wrfxpy, Coupled fire-atmosphere modeling, Web portal, Automatic setup

\section{Introduction}

As the resolution of the weather forecasting models increases, the fire-atmosphere interactions and smoke plumes that had to be treated as sub-grid-scale processes requiring a simplified treatment through external parameterizations become explicitly resolvable on fine model grids. Thanks to improved computational capabilities, operational applications of coupled-fire atmosphere models have become increasingly feasible. The rapid increase in the resolution of numerical weather prediction products observed over recent years has opened new avenues for development and implementations of integrated systems (e.g. WRF-SFIRE-CHEM; Kochanski et. al., 2016) that resolve in a fully coupled way fire progression, plume rise, smoke dispersion, and chemical transformations. In this paper, we present an integrated wildland fire forecasting system based on a high-resolution, multi-

Advances in Forest Fire Research 2018 - Page 950 
scale weather forecasting model coupled with a semi-empirical fire spread model and a prognostic dead fuel moisture model.

\section{Description of the simulation system}

The core of this forecasting framework is WRF-SFIRE (Mandel et al., 2009, 2011, 2014a), which is a coupled fire-atmosphere model based on the Weather Research and Forecasting model (WRF; Skamarock et al., 2008) and the Rothermel (1972) fire-spread model implemented using a level set method to evolve the fire front on a Eulerian grid in time. WRF-SFIRE evolved from CAWFE (Clark et al. 2004) and it has been a part of WRF release as WRF-Fire since 2011 (Mandel et al. 2011; Coen et al 2013). WRF-Fire was recently selected as foundation of the Colorado Fire Prediction System (CO-FPS) and the level set method in WRF release was improved (Muñoz-Esparza et al. 2018).

Fire-emitted heat and moisture fluxes computed at the fire mesh are integrated into WRF's coarser mesh. The fluxes affect the atmospheric state, thereby changing local winds that drive fire propagation (Mandel et al. 2011).

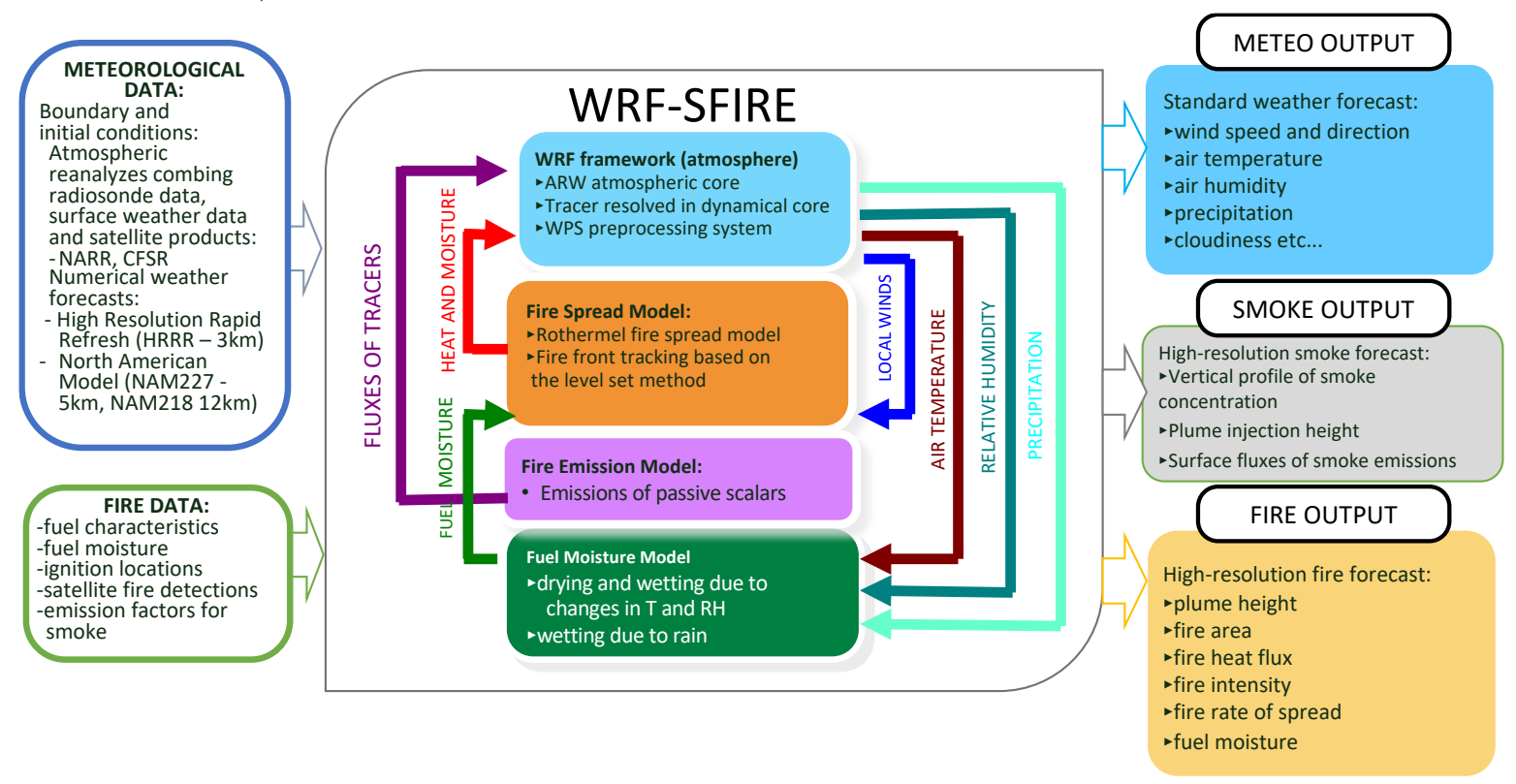

Figure 1 - Schematic of the WRF-SFIRE modeling system.

WRF-SFIRE is also coupled to a prognostic fuel moisture model, which assesses the moisture based on local WRF meteorology (air humidity, temperature, and precipitation (Mandel et al. 2014a). WRFSFIRE is designed to simulate the landscape-scale physics of the coupled fire-atmosphere phenomena and focuses on the importance of rapidly changing meteorological conditions at the fire line by taking into account local feedbacks between the fire, fuel, terrain, and the evolving atmospheric boundary layer. It can be driven by operational numerical weather prediction products to generate downscaled weather forecasts at a resolution of several hundred meters that resolve small-scale interactions between, for example, thunderstorm outflows, terrain, and fire. WRF-SFIRE is capable of simulating large-scale, high-intensity fires, under various topographical, meteorological, and vegetation conditions (Kochanski et al., 2013). Through the two-way coupling, WRF-SFIRE resolves basic fireatmosphere feedbacks, pyro-convection, and plume rise without relying on an external plume parameterization. A schematic of the WRF-SFIRE modeling system is presented in Figure 1. 


\section{The WRFX System}

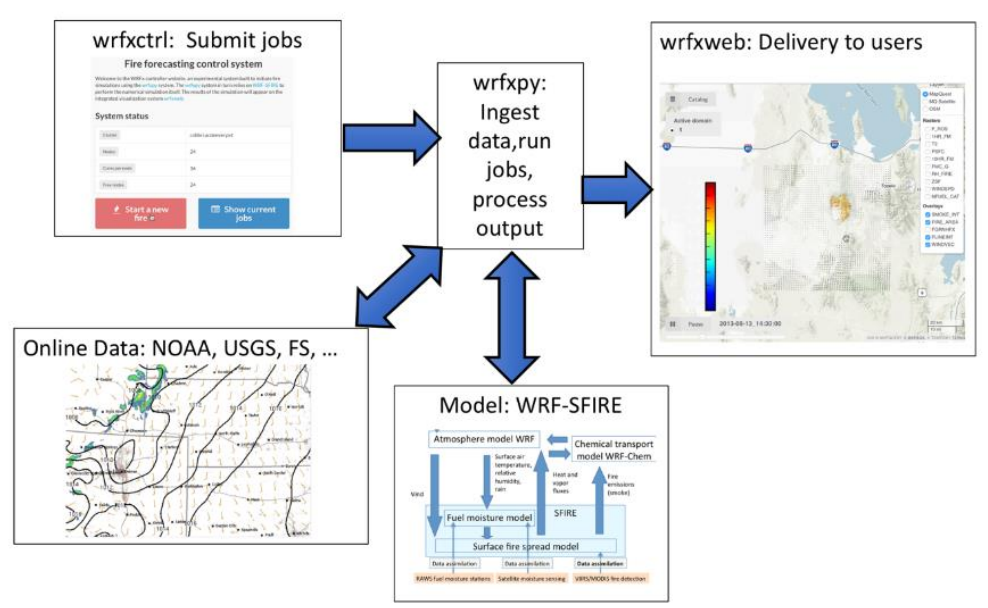

Figure 2 - The WRFX simulation management system.

\section{Description of the management system and web portal}

The WRFX system built around WRF-SFIRE enables automated real-time fire simulations and visualization of the model output. WRFX is a successor of an earlier prototype integrated system (Beezley et al. 2012). WRFX is comprised of three main modules: wrfctrl which allows the user to define simulation parameters and launch the forecast through the web interface, wrfxpy responsible for data collection, preprocessing, job submission, and visualization, and wrfxweb which displays the forecast on the web (Figure 2).

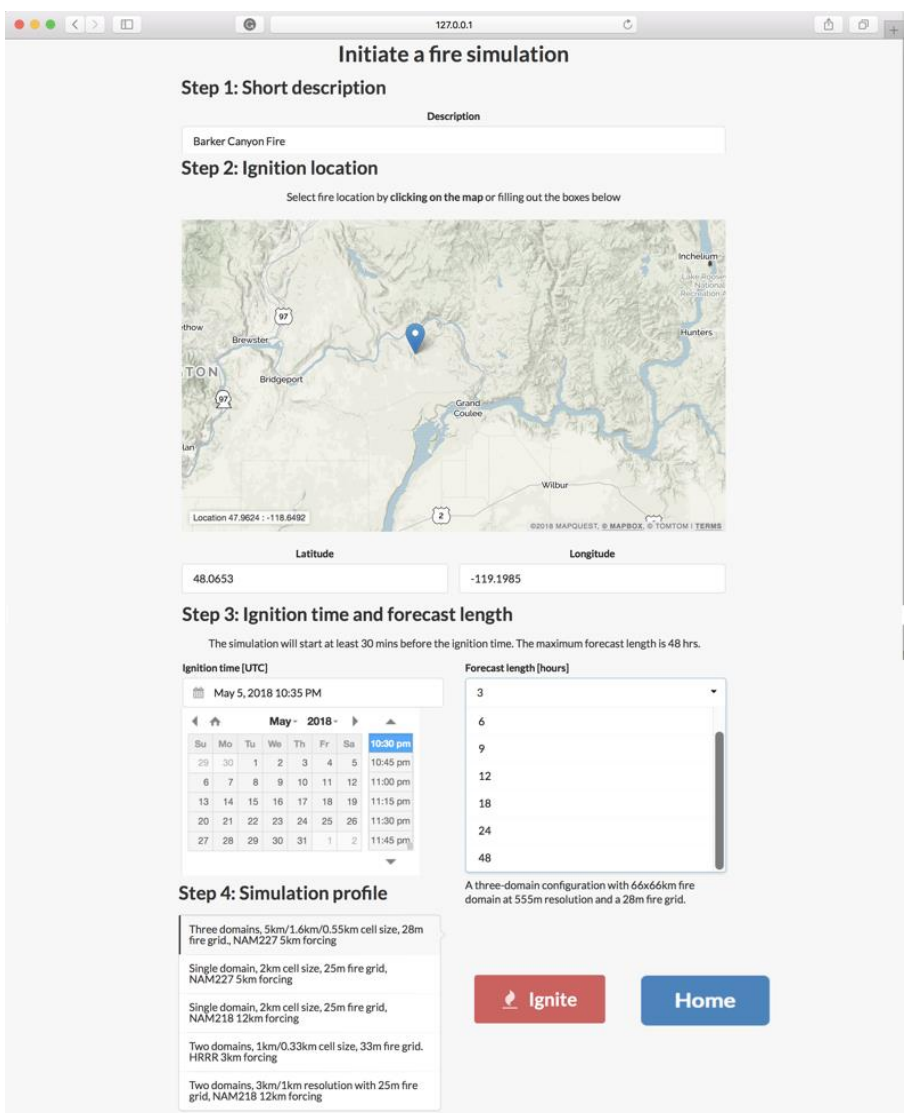

Figure 3. The wrfxctrl module used to define simulation parameters and initiate a forecast. 
Table 1 - Weather products integrated with the system.

\begin{tabular}{|l|l|l|}
\hline Weather product & Resolution & Forecast length \\
\hline North American Model NAM 218 & $12 \mathrm{~km}$ & 84 hours \\
\hline North American Model NAM 227 & $5 \mathrm{~km}$ & 60 hours \\
\hline High Resolution Rapid Refresh (HRRR) & $3 \mathrm{~km}$ & 36 hours \\
\hline North American Regional Analysis (NARR) & $32 \mathrm{~km}$ & Hindcast only \\
\hline Climate Forecast System Reanalysis (CFSR) & $38 \mathrm{~km}$ & Hindcast only \\
\hline
\end{tabular}

Fire simulation monitoring

\begin{tabular}{|c|c|c|c|}
\hline nformation & & Home & List jobs \\
\hline Current time & Fri, July 6th 2018, 14:52:56 & & \\
\hline WRF state & waiting & & \\
\hline Simulation started & 3 minutes ago & & \\
\hline Ignition coordinates & $40.3883,-112.6748$ & & \\
\hline Ignition time & 2018-07-06_20:47:00 UTC & & \\
\hline Forecast length & 24 hours & & \\
\hline Short description & test patch & & \\
\hline Simulation start time & 2018-07-06_20:00:00 UTC & & \\
\hline Simulation end time & 2018-07-07_20:00:00 UTC & & \\
\hline System identifier & from-web-2018-07-06_20-49-57 & & \\
\hline Visualization & no visualization & & \\
\hline
\end{tabular}

Detailed status

\begin{tabular}{|l|l|}
\hline GEOGRID & Running \\
\hline Ingest & Success \\
\hline UNGRIB & Success \\
\hline METGRID & Waiting \\
\hline REAL & Waiting \\
\hline WRF & Wa \\
\hline Output & Waiting \\
\hline
\end{tabular}

Event log

Figure 4 - Monitoring of wrfpy job execution by wrfxtrl.

The wrfctrl module enables the user to define the fire location, the start date of the forecast, its length, as well as domain configuration and the source of weather data to be used. A sample screenshot of the wrfctrl portal is presented in Figure 3. The forecast information provided by the user is fed to the wrfxpy module that performs additional steps needed to prepare the forecast. Once the fire is 'ignited', wrfxpy automatically generates a set of nested domains around the defined ignition location and starts data preprocessing tasks and then WRF execution, which are all monitored by wrfxctrl (Figure 4). 
As a first step, static data such as land use classification, soil type, vegetation type, fuel type, and elevation are interpolated to the model grids. The fuel and moisture data at $30 \mathrm{~m}$ resolution are stored locally as GeoTIFF files covering the whole contiguous U.S., so they can be accessed quickly without any delays associated with the data download from external sources. In parallel to the static data processing, wrfxpy acquires large-scale meteorological data, decompresses it and interpolates horizontally to the model grid. The currently supported meteorological sources are listed in Table 1.

Once the data are acquired and processed, wrfxpy generates WRF input and boundary condition files and submits a job to the queuing system on a computing cluster whch runs the forecast. The forecast length is limited by the length of the weather product used to generate boundary conditions. The wrfxctrl module contains a catalog of previous simulations initiated in wrfxctrl, so the user can monitor multiple simulations and manage currently running as well as past simulations (Figure 5).

\section{List of fire simulations}

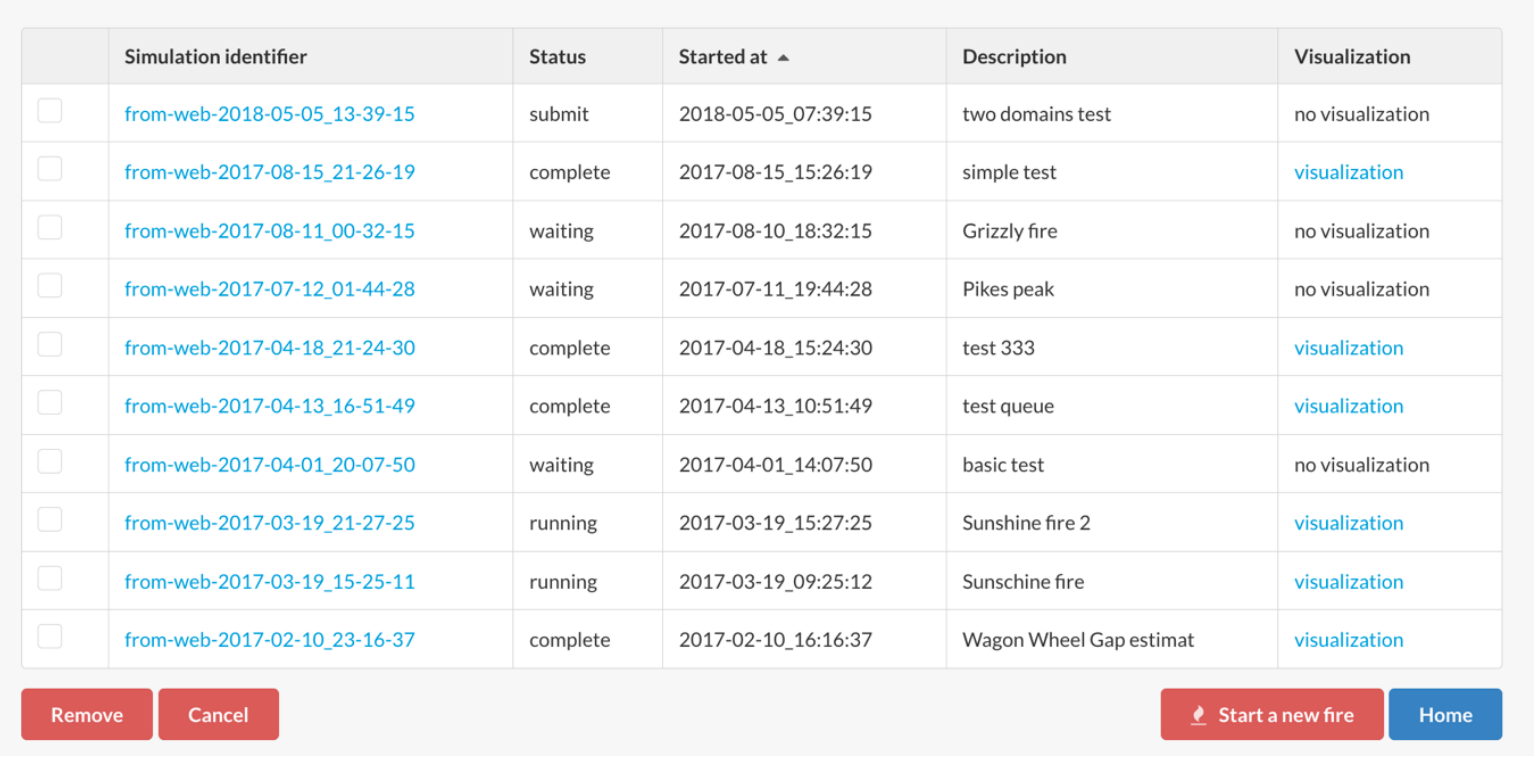

Figure 5 - Managing the simulations from the webcontrol interface wrfxctrl.

After the simulation job is submitted, the system controls the progression of the job, generates visualizations, and uploads them to wrfxweb. The portal enables easy access to the forecast, and progressively displays additional time frames as the simulation progresses, so the users have access to the partial forecast even before the full simulation is completed (Figure 6). The forecast includes variables such as $10 \mathrm{~m}$ wind speed and direction, $2 \mathrm{~m}$ air temperature, fire area, fireline intensity, fire heat flux, surface pressure, smoke intensity, plume top height, and fuel moisture. Any of these variables can be displayed or hidden in the portal by turning the particular forecast layer on or off, and animated using the time slider. Custom postprocessing and new layers, such as the plume height, used in Kochanski et al. (2018) can be easily added. The simulation to be displayed is selected from a catalog, which provides access any prior simulation stored in the wrfxweb subsystem.

The visualizations are also available for download as animated Google Earth files (Figure 7), where the simulation can be easily integrated with other information available in Google Earth format, such as satellite data. 


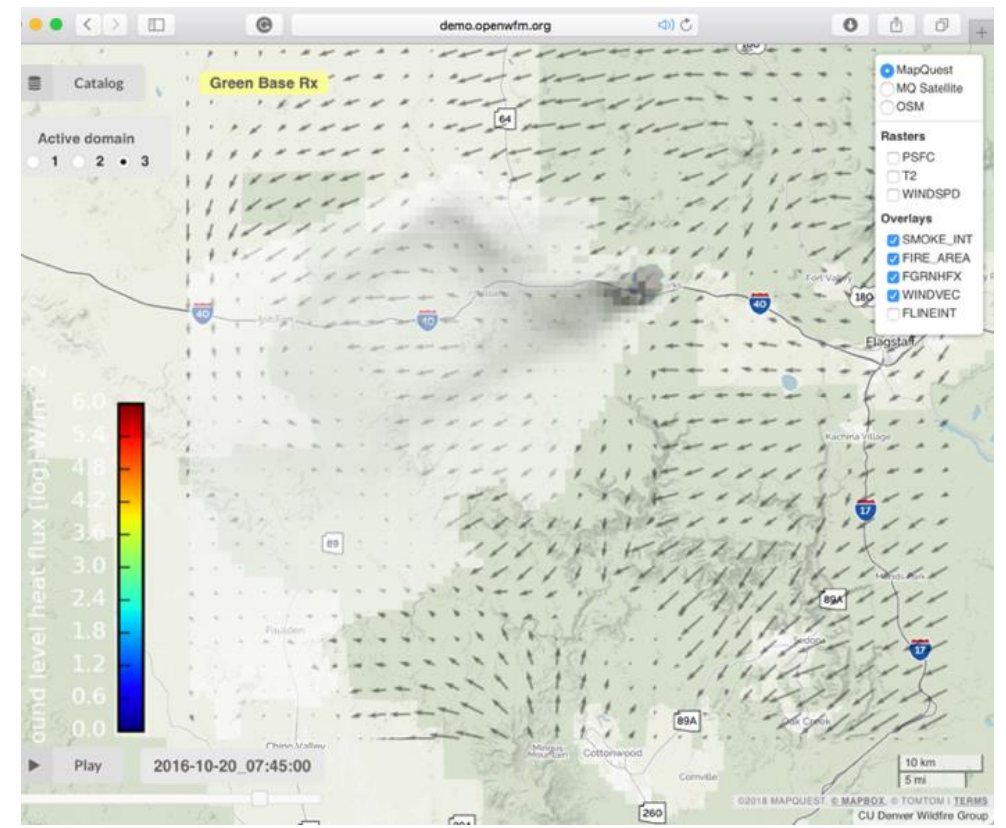

Figure 6 - WRFX web portal (wrfxweb) showing a sample visualization of a coupled fire atmosphere forecast.

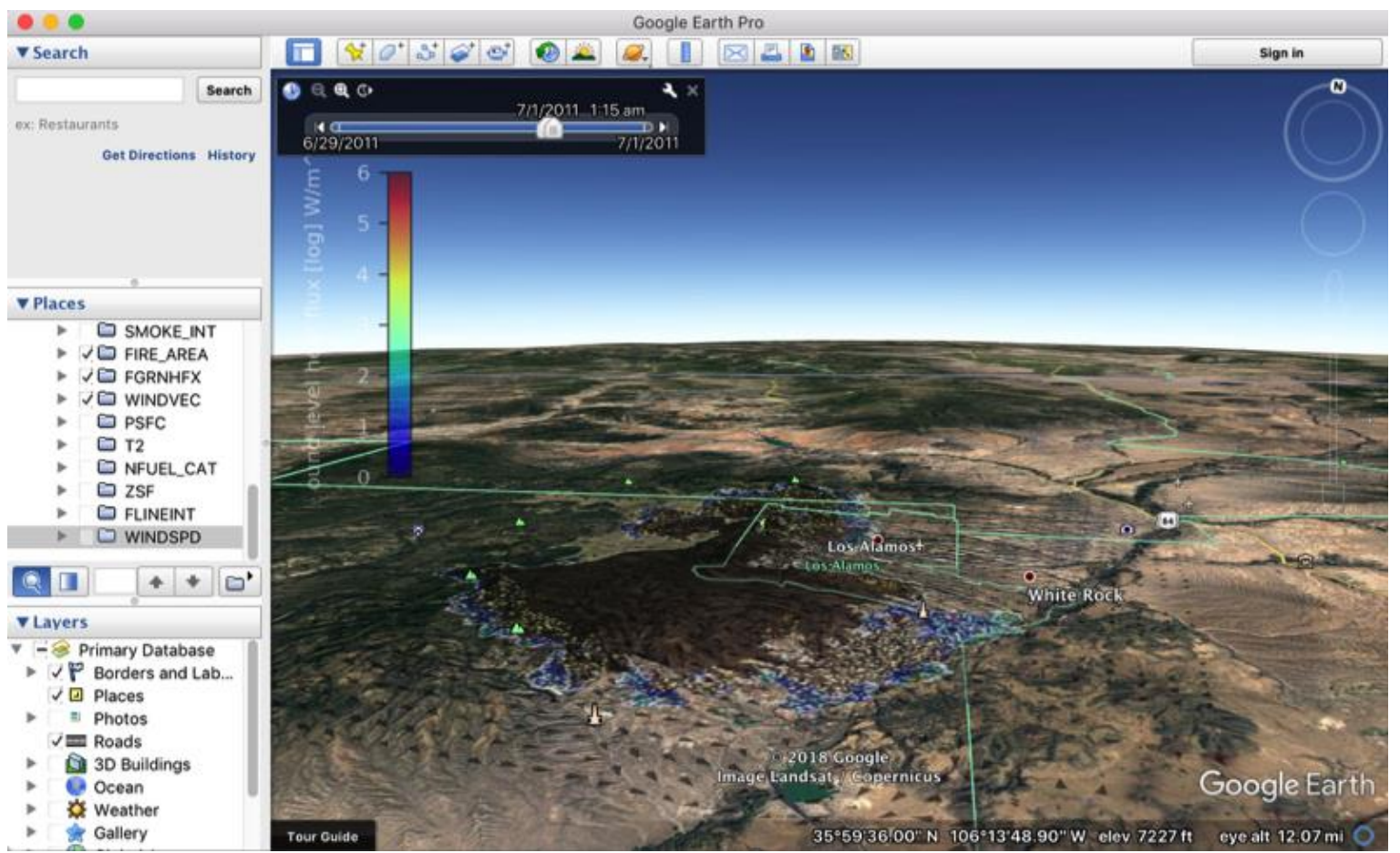

Figure 7 - An animated visualization in Google Earth (2011 Las Conchas fire).

The same wrfxweb portal also displays nowcast maps of the dead fuel moisture (Figure 8). They are computed for predefined geographical regions using the fuel moisture data assimilation system (Vejmelka et al., 2015), which automatically acquires and assimilates observations of dead fuel moisture by Remote Automated Weather Station (RAWS). 


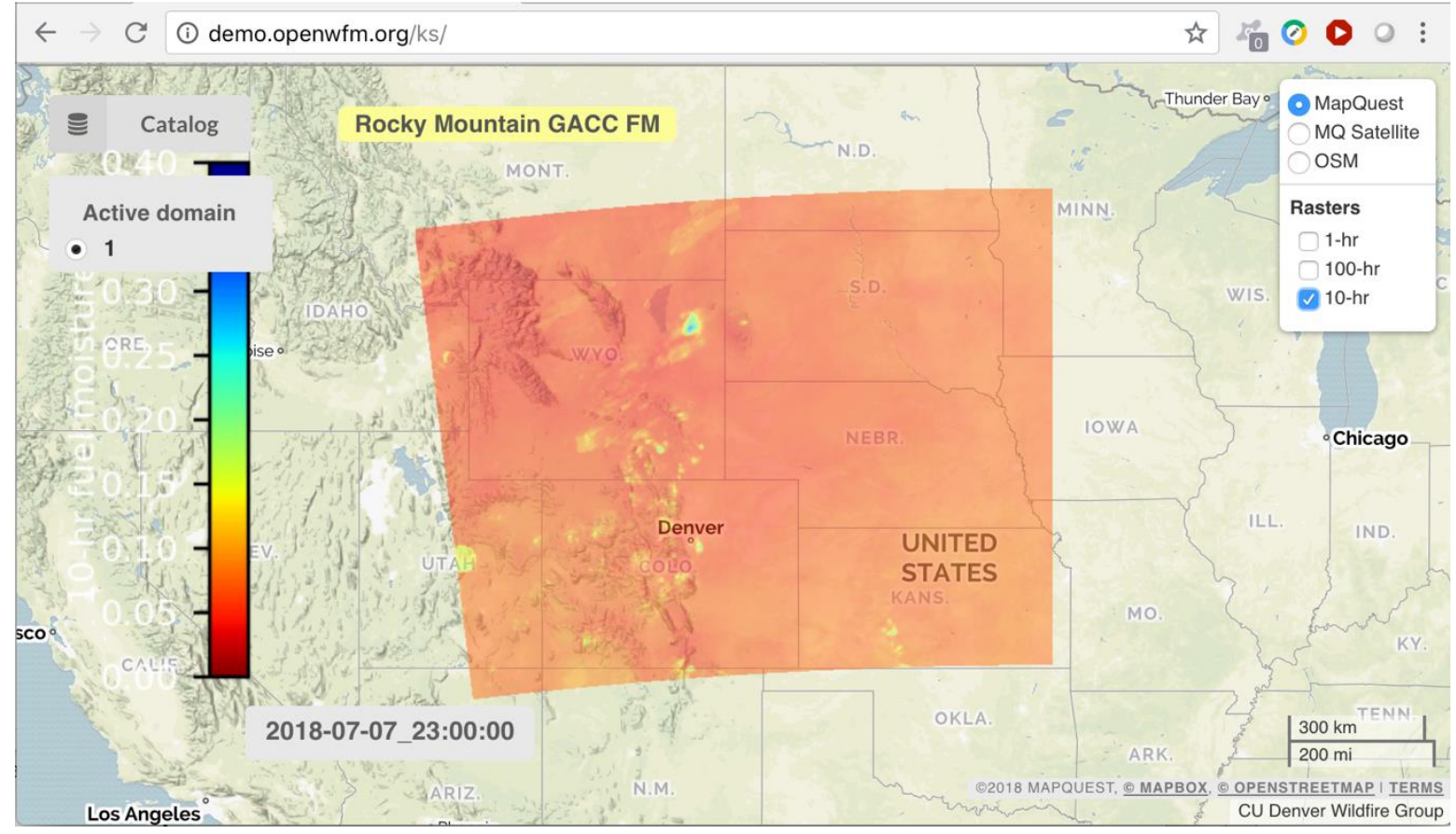

Figure 8 - Fuel moisture nowcasting from weather analysis and RAWS fuel moisture data assimilation.

\section{Conclusion and future plans}

In order to improve models like WRF-SFIRE, which utilize large-scale meteorology for the purpose of operational wildfire prediction, novel solutions must be applied to faithfully represent smaller-scale processes. The radiation and convective heat transfer from the fire to the atmosphere, the buoyancy effects on the fire-line winds, flow over complex terrain, changing fuel types, and structures (including canopies or individual trees and buildings) must be accounted for while remaining computationally viable. The ongoing work focuses on possible solutions in the form of coupling with complementary, reduced-physics diagnostic models such as QUIC-EnvSim (Overby et al., 2016). In this approach, the WRF model would be a source of coarser-scale weather data used to drive the prognostic QUIC model similarly as it was done for urban simulations presented in Kochanski et al. (2015). This coupling would enable better representation of the small-scale flow features driven by the terrain and the floe under a tree canopy. Additional endeavor aims at improvement of the fire-spread component of the system, such as replacing the Rothermel model with the Balbi (2009) model, improving the fuel consumption (e.g., fuel loads) and emissiona, through the integration with fuel consumption models using models that account for smoldering e.g., CONSUME 3.0 (Ottmar, 2009).As a flexible system of transparent Python scripts, WRFX is uniquely suited for extensions and integration of new functions.

The wrfxpy module can already acquire all relevant MODIS and VIIRS fire detection data for data assimilation. This module is currently in a transition to the new NASA https API access. The satellite products will be accessed by a uniform internal API, which will integrate additional data products, such as from GOES satellites (Koltunov et al., 2016). The visualization engine in WRFX enables an integration of the fire detections from various sources as additional layers.

Thus, WRFX can serve as a hub for research and implementation of data assimilation algorithms for coupled fire-atmosphere modeling, such as those in Mandel et al. (2014b, 2016). WRFX already includes a subsystem for initializing and monitoring of coupled fire-atmosphere simulations, which can be extended to manage analysis cycles, and spin-up for data assimilation. The ignition data from dispatch systems, such as IRWIN, and in principle even the effect of fire suppression actions can be 
likewise integrated into WRFX. The effect of fire suppression can be already modeled by hand modification of fuel maps, and WRFX supports restarting of hand-modified problems. Such modification can be automated and integrated into WRFX data preprocessing workflow.

The fuel moisture model with RAWS data assimilation is currently running in a standalone mode using Real Time Mesoscale Analysis (RTMA), which is available only for the present as a nowcast. Thus, the spin-up of the assimilated state has to happen in real time. In addition, the fuel moisture maps driven by the RTMA data can show artifacts, such as radar circles. We plan to switch to other data sources including the HRRR surface layer (HRRR is a forecast only product, but 3rd party archives exist) in order to support historical fuel moisture analyses and integrate the assimilated fuel moisture with the online fuel moisture model within WRF-SFIRE.

Both WRF-SFIRE and WRFX are publicly available at https://github.com.openwfm. The wrfxweb software is running at http://demo.openwfm.org provides visualization of test simulations as well as the near-real-time nowcasts of the dead fuel moisture.

\section{Acknowledgements}

This research was partially supported by NSF ICER-1664175 and NASA NNX13AH59G. The high-performance computing support from the Center for High Performance Computing at the University of Utah and Cheyenne (doi:10.5065/D6RX99HX) at NCAR Computational and Information Systems Laboratory, sponsored by the NSF, are gratefully acknowledged.

\section{References}

Balbi JH, Morandini F, Silvani X, Filippi JB, Rinieri F (2009), A physical model for wildland fires, Combustion and Flame 156, 2217-2230. doi:10.1016/j.combustflame.2009.07.010

Beezley JD, Martin M, Rosen P, Mandel J, Kochanski AK (2012) Data management and analysis with WRF and SFIRE. In 2012 IEEE Interntional Geoscience and Remote Sensing Symposium (IGARSS), 5274-5277, IEEE. doi: 10.1109/IGARSS.2012.6352419

Clark TL, Coen J, Latham D (2004) Description of a coupled atmosphere-fire model. International Journal of Wildland Fire 13, 49-63. doi:10.1071/WF03043

Coen JL, Cameron M, Michalakes J, Patton EG, Riggan PJ, Yedinak KM (2013) WRF-Fire: Coupled weather-wildland fire modeling with the Weather Research and Forecasting model. Journal of Applied Meteorology and Climatology 52, 16-38. doi:10.1175/JAMC-D-12-023.1

Kochanski AK, Jenkins MA, Krueger SK, Mandel J, Beezley JD (2013) Real time simulation of 2007 Santa Ana fires. Forest Ecology and Management 15, 136-149. doi: 10.1016/j.foreco.2012.12.014

Kochanski AK, Pardyjak ER. , Stoll R, Gowardhan A. , Brown MJ., and Steenburgh WJ., (2015) Oneway coupling of the WRF-QUIC urban dispersion modeling system. $J$. Appl. Meteorol. Climat., 52, 2119-2139, 2015. doi: 10.1175/JAMC-D-15-0020.1

Kochanski AK, Jenkins MA, Yedinak K, Mandel J, Beezley J, Lamb B (2016) Toward an integrated system for fire, smoke, and air quality simulations. International Journal of Wildland Fire 25, 534546. doi: 10.1071/WF14074

Kochanski AK, Fournier A, Mandel J (2018) Experimental Design of a Prescribed Burn Instrumentation, arXiv:1806.06460. Submitted to Atmosphere.

Koltunov A, Ustin SL, Quayle B, Schwind B, Ambrosia VG, Li W (2016) The development and first validation of the GOES Early Fire Dectection (GOES-EFD) algorithm. Remote Sensing Environment, 184, 436-453, doi: 10.1016/j.rse.2016.07.021 
Mandel J, Beezley JD, Coen JL, Kim M (2009) Data assimilation for wildland fires: Ensemble Kalman filters in coupled atmosphere-surface models. IEEE Control Systems Magazine 29, 47-65. doi:10.1109/MCS.2009.932224

Mandel J, Beezley JD, and Kochanski AK (2011) Coupled atmosphere-wildland fire modeling with WRF 3.3 and SFIRE 2011. Geoscientific Model Development 4, 591-610. doi: 10.5194/gmd-4591-2011

Mandel J, Amram S, Beezley JD, Kelman G, Kochanski AK, Kondratenko VY, Lynn BH, Regev B, Vejmelka M (2014a) Recent advances and applications of WRF-SFIRE. Natural Hazards and Earth System Science 14, 2829-2845. doi:10.5194/nhess-14-2829-2014

Mandel J, Kochanski AK, Vejmelka M, Beezley JD (2014b) Data assimilation of satellite fire detection in coupled atmosphere-fire simulations by WRF-SFIRE. Advances in Forest Fire Research, D. X. Viegas, ed., Coimbra University Press, 716-724. doi:10.14195/978-989-26-0884-6_80

Mandel J, Fournier A, Jenkins MA, Kochanski AK, Schranz S, Vejmelka M (2016) Assimilation of satellite active fires detection into a coupled weather-fire model. Proceedings for the 5th International Fire Behavior and Fuels Conference April 11-15, 2016, Portland, Oregon, USA, International Association of Wildland Fire, Missoula, Montana, USA, 17-22, http://www.iawfonline.org/proceedings.php.

Muñoz-Esparza D, Kosović B, Jiménez PA, Coen JL (2018) An accurate fire-spread algorithm in the Weather Research and Forecasting model using the level-set method. Journal of Advances in Modeling Earth Systems 10, 908-926. doi: 10.1002/2017MS001108

Overby M, Willemsen P, Bailey BN, Halverson S, and Pardyjak ER (2016) A rapid and scalable radiation transfer model for complex urban domains. Urban Climate 15, 25-44. doi: 10.1016/j.uclim.2015.11.004

Ottmar R (2009) Consume 3.0 - a software tool for computing fuel consumption. Fire Science Brief 55, 1-6, June 2009. Available at http://www.firescience.gov/projects/98-1-9-06/supdocs/98-1-906_FSBrief55-Final.pdf

Rothermel RC (1972) A mathematical model for predicting fire spread in wildland fires. USDA Forest Service Research Paper INT-115.

Skamarock WC, Klemp JB, Dudhia J, Gill DO, Barker DM, Duda MG, Huang X-Y, Wang W, and Powers JG (2008) A description of the Advanced Research WRF version 3. NCAR Technical Note 475. doi:10.5065/D68S4MVH

Vejmelka M, Kochanski AK, Mandel J (2016) Data assimilation of dead fuel moisture observations from remote automatic weather stations. International Journal of Wildland Fire 25, 558-568. doi:10.1071/WF14085 